\title{
Scenario Analysis of Hybrid Class 3-7 Heavy Vehicles
}

\author{
Feng An, Frank Stodolsky, Anant Vyas, and Roy Cuenca \\ Argonne National Laboratory
}

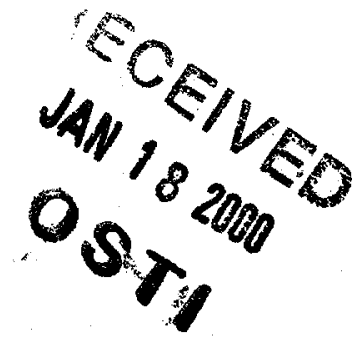

James J. Eberhardt

U.S. Department of Energy

\section{ABSTRACT}

The effects of hybridization on heavy-duty vehicles are not well understood. Heavy vehicles represent a broader range of applications than light-duty vehicles, resulting in a wide variety of chassis and engine combinations, as well as diverse driving conditions. Thus, the strategies, incremental costs, and energy/emission benefits associated with hybridizing heavy vehicles could differ significantly from those for passenger cars. Using a modal energy and emissions model, we quantify the potential energy savings of hybridizing commercial Class 3-7 heavy vehicles, analyze hybrid configuration scenarios, and estimate the associated investment cost and payback time. From our analysis, we conclude that (1) hybridization can significantly reduce energy consumption of Class 3-7 heavy vehicles under urban driving conditions; (2) the grid-independent, conventional vehicle (CV) -like hybrid is more cost-effective than the grid-dependent, electric vehicle (EV) -like hybrid, and the parallel configuration is more cost-effective than the series configuration; ( 3 ) for CV-like hybridization, the onboard engine can be significantly downsized, with a gasoline or diesel engine used for SUVs perhaps being a good candidate for an on-board engine; (4) over the long term, the incremental cost of a CV-like, parallelconfigured Class 3-4 hybrid heavy vehicle is about $\$ 5,800$ in the year 2005 and $\$ 3,000$ in 2020 , while for a Class 6-7 truck, it is about $\$ 7,100$ in 2005 and $\$ 3,300$ in 2020; and (5) investment payback time, which depends on the specific type and application of the vehicle, averages about 6 years under urban driving conditions in 2005 and $2-3$ years in 2020.

\section{INTRODUCTION}

Numerous analyses, research and demonstration efforts, and laboratory tests have been conducted to help clarify the energy and emission benefits of hybridizing light-duty vehicles [1-5]. However, understanding of how hybridization affects heavy-duty vehicles is limited, primarily because
1. Heavy vehicles represent a much broader range of vehicle applications than light-duty vehicles, resulting in a wide variety of vehicle chassis and engine combinations.

2. Because of their varied applications, heavy vehicles also encounter more diverse driving conditions, which are much more difficult to characterize.

3. On U.S. highways, Class 8 heavy-duty trucks dominate commercial trucking energy consumption, overshadowing Class 3-7 commercial vehicles.

The hybridization of Class 8 long-haul highway trucks is less favorable in terms of energy savings because the engines typically operate at high efficiency under conditions of steady speeds and high loads. However, a number of demonstration projects exist around the world for hybrid urban transit buses and delivery trucks [6]. These vehicles, which are usually engaged in stop-andgo driving, are ideal candidates for hybridization.

We seek to quantify potential energy savings of hybridizing commercial Class 3-7 heavy vehicles, analyze hybrid configuration scenarios, and estimate the associated investment cost and payback time. In this paper, we (1) characterize conventional Class 3-7 heavy vehicles, (2) present an overview of today's hybrid vehicle technologies as applied to light-duty vehicles, (3) establish scenarios for hybrid heavy vehicle configurations, (4) assess hybrid heavy vehicle energysaving potentials, and (5) estimate the incremental investment cost of hybridization and simple payback time.

\section{CHARACTERISTICS OF CONVENTIONAL CLASS 3-7 HEAVY-DUTY VEHICLES}

Class 3-7 commercial vehicles represent a broad range of vehicle applications, including but not limited to parcel delivery, utility/service, towing/emergency, ambulance and shuttle buses, motor home chassis, and school buses. Their annual sales are much lower than those of 


\section{DISCLAIMER}

This report was prepared as an account of work sponsored by an agency of the United States Government. Neither the United States Government nor any agency thereof, nor any of their employees, make any warranty, express or implied, or assumes any legal liability or responsibility for the accuracy, completeness, or usefulness of any information, apparatus, product, or process disclosed, or represents that its use would not infringe privately owned rights. Reference herein to any specific commercial product, process, or service by trade name, trademark, manufacturer, or otherwise does not necessarily constitute or imply its endorsement, recommendation, or favoring by the United States Government or any agency thereof. The views and opinions of authors expressed herein do not necessarily state or reflect those of the United States Government or any agency thereof. 


\section{DISCLAIMER}

Portions of this document may be illegible in electronic image products. Images are produced from the best available original document. 
Class 1-2 light-duty trucks, but higher than those of Class 8 heavy-duty trucks. Table 1 shows U.S. heavy truck sales in 1997 [7].

Table 1. U.S. Truck Sales in 1997

\begin{tabular}{c|c|cc}
\hline $\begin{array}{c}\text { Market } \\
\text { Segment }\end{array}$ & $\begin{array}{c}\text { GVW } \\
\text { Class }\end{array}$ & $\begin{array}{c}\text { Actual } \\
\text { Units }\end{array}$ & $\begin{array}{c}\text { Share } \\
(\%)\end{array}$ \\
\hline Medium-Duty & $3-5$ & 118,600 & 27.6 \\
Medium-Heavy & $6-7$ & 131,800 & 30.7 \\
Heavy-Heavy & 8 & 178,600 & 41.6 \\
\hline Total Heavy Trucks & $3-8$ & 429,000 & 100.0 \\
\hline
\end{tabular}

Table 1 shows that annual sales of medium Class 3-5 trucks in 1997 were about 119,000 units, or $-28 \%$ of the total truck market. Annual sales of medium-heavy Class 6-7 trucks in 1997 were about 132,000 units, or $~ 31 \%$ of total heavy trucks. Thus, the total units of Class 3-7 heavy vehicles sold in 1997 were about 250,000 , or $-58 \%$ of total units of Class 3-8 heavy trucks.

\section{REPRESENTATIVE VEHICLES}

Unlike light-duty vehicle manufacturers, heavy-duty vehicle manufacturers do not necessarily make their own engines. Consequently, there is considerable flexibility in choosing different combinations of vehicle chassis and engines. In this analysis, we chose two vehicle chassis and engine combinations as our baseline vehicles: (1) a Class 3-4 Ford E-super duty chassis parcel-delivery truck with a Navistar T444 E 7.3-L TDI diesel V8 engine and (2) a Class 6-7 Navistar 300 series truck (i.e., a school bus or medium heavy truck) with a Navistar T466 $E$ 7.7-L TDI diesel in-line 6 engine. These two combinations were selected because the vehicles are widely used and engine data are available. Table 2 shows some basic characteristics of these two vehicles. In the following analysis, the Class 3-4 vehicle is modeled with $14,000 \mathrm{lb}$ GVWR, and the Class 6-7 vehicle is modeled with $26,000 \mathrm{lb}$ GVWR.

\section{HEAVY-DUTY VEHICLE DRIVING CYCLES}

For light-duty vehicles, fuel consumption and emissions are extremely sensitive to different test cycles [3]. For heavy-duty vehicles, the dependence of fuel economy and emissions performance on test cycles can be even greater, mainly because heavy vehicles are used more diversely. Thus, it is critical to understand how heavy vehicles are driven under real-world conditions. We have identified five existing urban test cycles for heavy-duty vehicles, as follows [8]:
1. $\quad \mathrm{CBD}$ - Central Business District (CBD) Cycle
2. CBDtrk - CBD Truck Cycle.
3. NYbus - New York City Bus Cycle
4. NYtrk - New York City Truck Cycle
5. NYGTC - New York City Garbage Truck Cycle

Because these cycles have very diverse characteristics, they should provide useful insights for our study. Table 3 lists some characteristics of these five heavy-duty vehicle test cycles.

Table 2. Characteristics of Two Representative Vehicles

\begin{tabular}{|c|c|c|}
\hline Item & $\begin{array}{c}\text { Class 3-4 Mid- } \\
\text { Range Truck }\end{array}$ & $\begin{array}{c}\text { Class 6-7 } \\
\text { Medium Truck } \\
\text { School Bus }\end{array}$ \\
\hline GVW rating & $10,000-16,000 \mathrm{lb}$ & $19,500-33,000 \mathrm{lb}$ \\
\hline Model weight & $14,000 \mathrm{lb}$ & $26,000 \mathrm{lb}$ \\
\hline Engine & $\begin{array}{c}\text { Navistar T } 444 \text { E } \\
7.3 \text { L TDI Diesel V8 } \\
190 \text { hp @ } 2300 \text { rpm } \\
430 \text { lb-ft @ } 1500 \\
\text { rpm }\end{array}$ & $\begin{array}{c}\text { Navistar T } 466 \text { E } \\
7.7 \text { L TDI Diesel I-6 } \\
210 \text { hp @ } 2300 \text { rpm } \\
520 \text { lb-ft @ } 1500 \text { rpm }\end{array}$ \\
\hline $\begin{array}{c}\text { Min. bsfc } \\
\text { (peak eng. eff.) } \\
\text { Fuel tank }\end{array}$ & $\begin{array}{c}210 \mathrm{~g} / \mathrm{kWh} \\
(39 \%) \\
37.0 \mathrm{gal}\end{array}$ & $\begin{array}{c}210 \mathrm{~g} / \mathrm{kWh} \\
(39 \%) \\
35.0 \mathrm{gal}\end{array}$ \\
\hline $\begin{array}{c}\text { Transmission } \\
\text { Gear ratio } \\
\text { Tire }\end{array}$ & $\begin{array}{c}\text { A4 Overdrive E4OD } \\
2.71 / 1.54 / 1.00 / 0.71 \\
215 / 85 \mathrm{R} 16(\text { radius }= \\
0.355 \mathrm{~m})\end{array}$ & $\begin{array}{c}\text { Allison AT-545, A4 } \\
3.45 / 2.25 / 1.41 / 1.00 \\
\text { 10R22.5 (radius = } \\
0.459 \mathrm{~m} \text { ) }\end{array}$ \\
\hline $\begin{array}{l}\text { Coeff. of drag, } \\
\text { Cd }\end{array}$ & 0.45 & 0.6 \\
\hline $\begin{array}{l}\text { Coeff. of rolling } \\
\text { resistance, } \mathrm{Cr}\end{array}$ & 0.01 & 0.01 \\
\hline Frontal area $\left(\mathrm{m}^{2}\right)$ & 3.0 & 5.4 \\
\hline
\end{tabular}

Table 3. Characteristics of Five Heavy-Duty Vehicle Drive Cycles

\begin{tabular}{|c|cccccc|}
\hline Cycle & $\begin{array}{c}\text { Time } \\
(s)\end{array}$ & $\begin{array}{c}D \\
(\mathrm{mi})\end{array}$ & $\begin{array}{c}\langle v\rangle \\
(\mathrm{mph})\end{array}$ & $\begin{array}{c}v_{\max } \\
(\mathrm{mph})\end{array}$ & $\begin{array}{c}a_{\max } \\
(\mathrm{mph} / \mathrm{s})\end{array}$ & $\begin{array}{c}K_{\max } \\
\left(\mathrm{mph}^{2} / \mathrm{s}\right)\end{array}$ \\
\hline CBD & 574 & 2.0 & 12.6 & 20.0 & 2.4 & 68.0 \\
CBDtrk & 854 & 2.2 & 9.2 & 20.0 & 0.8 & 24.0 \\
NYbus & 600 & 0.6 & 3.7 & 30.8 & 6.2 & 198.7 \\
NYtrk & 1016 & 2.1 & 7.6 & 34.0 & 4.4 & 221.0 \\
NYGTC & 585 & 0.4 & 2.3 & 20.0 & 3.0 & 65.5 \\
\hline
\end{tabular}

In Table 3, the Time column gives the duration of the cycles in seconds, $D$ is the length of each cycle in miles, $\langle v\rangle$ is the average speed in miles per hour (mph), $v_{\max }$ is the maximum speed in mph, $a_{\max }$ is the maximum acceleration rate in $\mathrm{mph} / \mathrm{s}$, and $\mathrm{K}_{\max }$ is the maximum specific energy $K$ in $\mathrm{mph}^{2} / \mathrm{s}$. $K$, defined as twice the velocity times the acceleration rate $\left(2^{*} v^{*} a\right)$, measures the rate of change of a vehicle's kinetic energy.

\section{FUEL ECONOMY OF HEAVY VEHICLES}

On the basis of an established vehicle modal energy and emissions model (MEEM) [9-11] and on fuel consumption and emission maps for the Navistar T444E diesel engine ${ }^{1}$ (obtained through Oak Ridge National

\footnotetext{
1 The engine T466E map for the Class 6-7 vehicle is obtained from the T444E engine and a scaling routine in the MEEM.
} 
Laboratory), we have calculated the fuel economy for these two baseline vehicles under the five different driving cycles (Table 4).

Table 4. Fuel Economy (mpg) of Two Baseline Vehicles under Five Different Driving Cycles

\begin{tabular}{c|c|c}
\hline Cycle & $\begin{array}{c}\text { Class 3-4 } \\
(\mathrm{mpg})\end{array}$ & $\begin{array}{c}\text { Class 6-7 } \\
\text { (mpg) }\end{array}$ \\
\hline CBD & 7.9 & 4.7 \\
CBDtrk & 8.2 & 5.0 \\
NYbus & 4.7 & 3.0 \\
NYtrk & 7.2 & 4.4 \\
NYGTC & 4.4 & 3.0 \\
\hline
\end{tabular}

Table 4 shows that the vehicle fuel economy varies significantly from cycle to cycle; for instance, the modeled fuel economy of the Class 3-4 truck ranges from $4.4 \mathrm{mpg}$ in the NYGTC to $8.2 \mathrm{mpg}$ in the CBDtrk cycle. For the Class 6-7 vehicles, the fuel economy ranges from $3.0 \mathrm{mpg}$ in the NYGTC and NYbus cycles to $5.0 \mathrm{mpg}$ in the CBDtrk cycle.

\section{PERFORMANCE CHARACTERISTICS OF HEAVY VEHICLES}

The performance characteristics of heavy vehicles are very different from those of light-duty vehicles. This section assesses the maximum gradeability and acceleration performance of Class 3-4 and Class 6-7 heavy vehicles, respectively.

\section{Maximum Gradeability Assessment}

Maximum gradeability decreases as the vehicle speed increases. Table 5 and Figure 1 show the modeling results for maximum gradeability of Class 3-4 and Class 6-7 vehicles as a function of vehicle cruising speed. For example, at a 30-mph cruising speed, the maximum gradeability is about $16 \%$ for a Class $3-4$ truck and $7 \%$ for a Class 6-7 truck. At a $60-\mathrm{mph}$ cruising speed, the maximum gradeability is only about $5 \%$ for a Class $3-4$ truck and less than $1 \%$ for a Class 6-7 truck.

Table 5 - Maximum Gradeability under Different Speeds

\begin{tabular}{|c|c|c|}
\hline Speed & \multicolumn{2}{|c|}{ Gradeability (\%) } \\
\cline { 2 - 3 } (mph) & Class 3-4 & Class 6-7 \\
10 & 24.9 & 10.5 \\
20 & 14.0 & 11.2 \\
30 & 15.5 & 6.6 \\
40 & 8.8 & 3.4 \\
45 & 8.9 & 3.1 \\
50 & 9.0 & 2.8 \\
55 & 5.0 & 2.4 \\
60 & 4.9 & 0.9 \\
\hline
\end{tabular}

On the basis of our modeling exercise, Figure 1 shows that the decrease in gradeability as a function of increased vehicle speed is not linear; it fluctuates as a result of gear shifting that occurs at various vehicle speeds. But the overall trends are decreasing linearly, as demonstrated by the two regression lines.

Figure 1 - Maximum Gradeability under Different Speeds

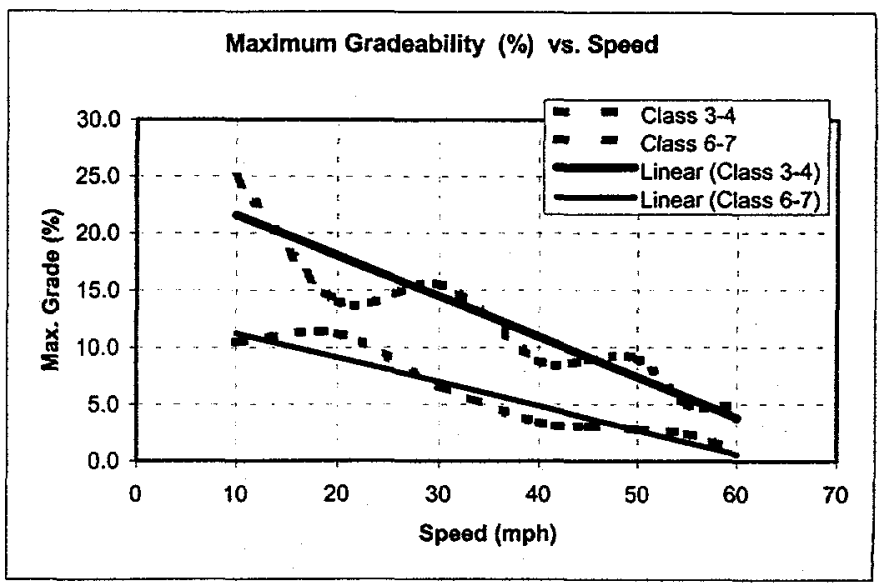

\section{Acceleration Performance Assessment}

Table 6 and Figure 2 show the acceleration time from 0 to given final speeds. According to our model, it takes 17 seconds to accelerate from 0 to $30 \mathrm{mph}$ for the Class 3-4 truck $(14,000 \mathrm{lb})$ and 36 seconds for the Class $6-7$ vehicle $(26,000 \mathrm{lb})$. To accelerate from 0 to $60 \mathrm{mph}$, it takes more than half a minute (32 s) for the Class $3-4$ truck and $83 \mathrm{~s}$ for the Class 6-7 vehicle. Compared to that of light-duty vehicles, the acceleration performance of heavy vehicles is very poor.

\section{Table 6 - Acceleration Time from 0 to Given Final Speeds}

\begin{tabular}{|c|c|c|}
\hline & \multicolumn{2}{|c|}{ Acc. Time (s) } \\
\cline { 2 - 3 } Final Speed (mph) & Class 3-4 & Class 6-7 \\
10 & 7 & 13 \\
20 & 13 & 28 \\
30 & 17 & 36 \\
40 & 21 & 47 \\
50 & 27 & 63 \\
60 & 32 & 83 \\
\hline
\end{tabular}

\section{OVERVIEW OF TODAY'S HYBRID TECHNOLOGIES}

This section overviews the current status of hybrid technologies, primarily based on knowledge and experience gained from hybridizing light-duty vehicles. We focus on three areas in our assessment: hybrid electric vehicle (HEV) configuration, categorization, and control strategies. 
HEV CONFIGURATION

Today's HEVs have three basic configurations: (1) a series HEV configuration (see Figure 3a), (2) a parallel HEV configuration (see Figure $3 b$ ), and (3) a power-split HEV configuration (see Figure $3 c$ ).

Figure 2 - Acceleration Time from 0 to Given Final Speeds

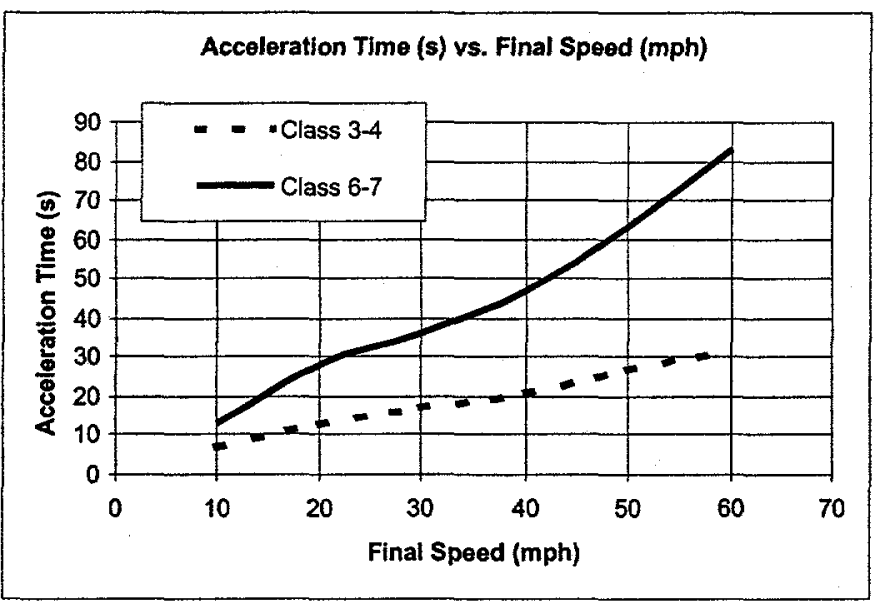

\section{Series-Configured HEV System}

In this type of configuration, the engine drives a generator, which produces electricity that powers a motor to drive the wheels and, during periods of low power demand, charges the battery. It is called a series hybrid because the power flows in a straight line.

Figure 3a. Series Configuration HEV

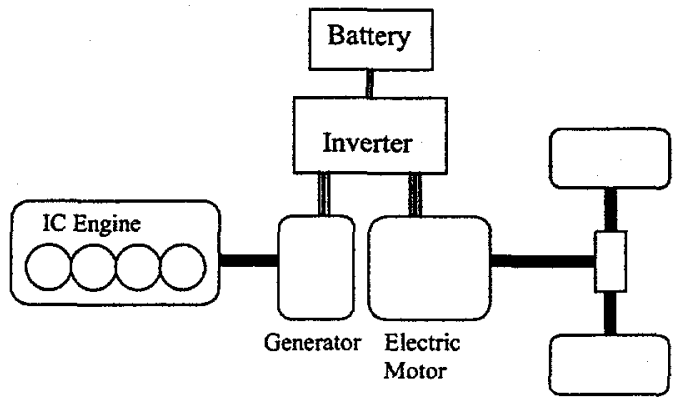

\section{Parallel-Configured HEV System}

In this type of configuration, both the engine and motor drive the vehicle wheels. Because the power flows along two paths, it is called a parallel system. This system also allows the engine to charge the battery on-board and recover braking energy.

\section{Power-Split HEV System}

This configuration is neither a parallel nor a series configuration. Closer to the parallel configuration, it differs in that a planetary gear system combined with a starter/generator can transfer power between the ICE and electric motor, which are coupled to the driveshaft. In this configuration, the ICE provides the primary power, with a power-split device (planetary gear with starter/generator), sending power to both the driveshaft and the electric motor.

Figure 3b. Parallel Configuration HEV

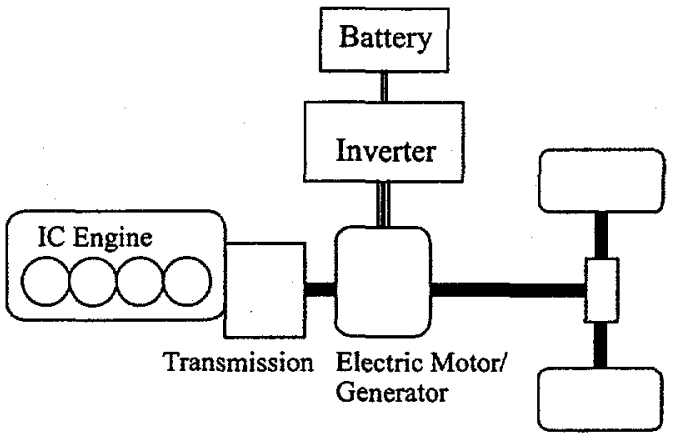

Figure 3c. Power-Split Configuration HEV

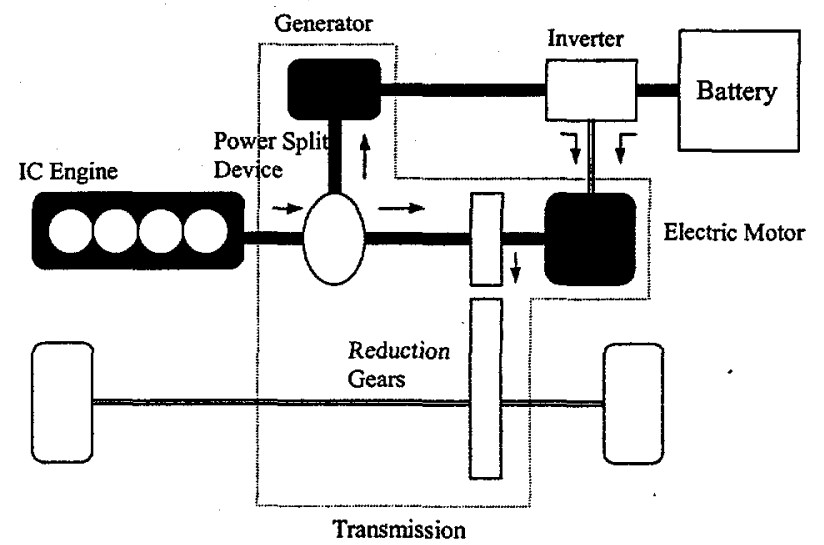

HYBRID VEHICLE CATEGORIZATION

There are many ways to categorize hybrid vehicle families. Here we are only interested in two types of hybrid vehicles: EV-like range-extender and CV-like power-assist HEVs.

\section{EV-like Range-Extender HEVs}

This concept starts with an electric vehicle (EV) and adds a conventionally fueled auxiliary power unit (APU) capable of providing additional tractive power and recharging the battery as needed. The fuel tank of the APU thus becomes an energy storage supplement to the batteries, which results in significant increases in driving range and power. The primary energy source is electricity from the power grid. The major advantage of an EV-like HEV is that it provides a significant pureelectric or zero-emission driving range. 
This concept starts with a conventional vehicle with an internal-combustion-engine (ICE) and modifies it, adding an auxiliary electric drivetrain and storage system to provide the flexibility needed to optimize energy management, as well as the means to recover braking energy. The power-assist HEV can be designed as either a parallel or a series system. The energy source is conventional gasoline or diesel fuel.

Three other key issues that also guide HEV categorization must be considered.

\section{Charge-Sustaining vs. Charge-Depleting}

It is important to determine whether the HEV can operate indefinitely without changing the battery's state of charge (SOC). If the HEV can operate and keep its battery charge at a specified level, it is referred to as a "charge-sustaining" HEV. If not, it is referred to as a "charge-depleting" HEV.

\section{Zero Emission Vehicle (ZEV) Operation Capability.}

If an HEV is capable of operating entirely in electricmode only (i.e., the on-board engine is not used), then it is referred to as ZEV-operation-capable. On the other hand, the electric motor may be sized too small for practical driving speeds to allow for ZEV operation; in such a case, the HEV is ZEV-operation-incapable.

\section{HEV CONTROL STRATEGY}

There are many conceivable control strategies for HEVs. The two examples considered below are the most popular ones.

\section{Thermostatic Strategy}

A "thermostatic" control strategy is usually applied to a series HEV, where the on-board engine drives a generator and its electrical output powers an electric motor that drives the wheels (and any accessories) when needed. The on-board engine usually operates at constant power output, at its maximum efficiency design point.

\section{Load-Following Control Strategy}

A "load-following" control strategy is probably the one most widely used for light-duty hybrid vehicles. Instead of operating the on-board engine at a single operating point, a load-following strategy allows the engine to operate within a range specified by the power demand, vehicle speed, and/or engine speed. A load-following strategy is particularly suitable for an on-board engine that does not go rich at wide-open-throttle (WOT), such as the Toyota Prius's 1.5-L engine). In this case, the engine is always more efficient when running closer to the WOT region.

\section{CONFIGURATION SCENARIOS OF HYBRID HEAVY VEHICLES}

The above section provides a basis for the discussion of hybridizing heavy-duty vehicles. Generally speaking, most HEVs under development fall into one of two categories:

1. CV-like, charge-sustaining HEVs with either parallel or series configurations. This kind of HEV combines a slightly downsized IC engine with a small auxiliary electric drivetrain and storage system to provide the flexibility needed to optimize energy management, as well as the means to recover braking energy. The energy source is gasoline or diesel; the battery will only be charged on-board to maintain a specified SOC range.

2. An EV-like, charge-depleting, series-configured HEV. This kind of HEV combines a large battery pack to provide significant ZEV range with a small engine for limp-home and on-board charging capability to extend the vehicle driving range. The primary energy source is grid electricity.

We will establish design criteria for each of these HEVs. Before designing a heavy hybrid vehicle, it is crucial to estimate the power and energy requirements of these vehicles under various urban driving cycles.

\section{POWER AND ENERGY REQUIREMENTS OF CLASS 3-7 HEAVY-DUTY VEHICLES}

\section{Power Demand at Given Speed and Grade}

The purpose of estimating power demand of heavy vehicles is to help determine the required power rating of on-board ICEs. For any hybrid design, the on-board ICE should be able to supply a certain degree of sustainable power to drive the vehicle alone. We have established the following criteria to determine the peak power of the on-board ICE:

- For a CV-like Class 3-4 commercial truck, the onboard ICE should be able to supply sufficient power to drive the vehicle at a $55-\mathrm{mph}$ constant speed on a $5 \%$ grade. For a CV-like Class 6-7 vehicle, the onboard ICE should be able to supply sufficient power to drive the vehicle at close to a $60-\mathrm{mph}$ constant speed on level ground.

- For an EV-like vehicle, the on-board ICE should be able to supply sưfficient power for vehicle limp-home capability. For a Class 3-4 truck, this means a 30mph cruising speed up a $5 \%$ grade. For a Class 6-7 vehicle, it means a 40-mph cruising speed on level ground.

Table 7 shows the power demand at several cruising speeds (10-60 mph) for a Class 3-4 truck with $5 \%$ grade and a Class 6-7 truck with $0 \%$ grade. The on-board ICE power requirement for a $\mathrm{CV}$-like Class 3-4 vehicle is 
about $98 \mathrm{~kW}$ (131 hp). For a CV-like Class 6-7 vehicle, the requirement is about $93 \mathrm{~kW}(125 \mathrm{hp})$.

Table 7 also shows that a $50 \mathrm{~kW}$ on-board engine is sufficient to provide "limp-home capability" for EV-like Class 3-4 and Class 6-7 vehicles.

\section{Heavy Vehicle Cycle Energy Demand}

We have also estimated the energy demand of heavy vehicles under various driving cycles. This information can be very useful for an EV-like hybrid vehicle design, where the battery pack is required to provide electrical energy to drive the vehicle for at least 30 miles.

Table 8 lists energy demand at vehicle wheels for the Class 3-4 medium truck and Class 6-7 truck/bus under diverse driving cycles. The energy demand is given in units of kWh for every 30 miles of driving. The table shows that, for a 30-mile pure-electric range, the energy demand from HEV battery packs would average about $25 \mathrm{kWh}$ for the Class 3-4 truck and $47 \mathrm{kWh}$ for the Class 6-7 truck.

Table 7. Power Demand (kW) under Cruising Speeds (10-60 mph) for a Class 3 Truck (with 5\% Grade) and a Class 6 Truck (with $0 \%$ Grade)

\begin{tabular}{|c|c|c|}
\hline \multirow{3}{*}{$\begin{array}{c}\text { Speed } \\
\text { (mph) }\end{array}$} & Class 3-4 & Class 6-7 \\
\cline { 2 - 3 } 10 & Power (kW) & Power (kW) \\
20 & (Grade =5\%) & (Grade = O\%) \\
30 & 14.5 & 6.3 \\
& 29.9 & 14.8 \\
40 & HE (limp-home EV-like & 26.5 \\
& 65.4 & \\
45 & 75.3 & engine power) \\
50 & HEV engine power) \\
55 & 96.5 & 52.8 \\
& 98 (CV-like HEV engine & 64.5 \\
60 & power) & 77.6 \\
& 110 & 93 (CV-like HEV engine \\
& & power) \\
\hline
\end{tabular}

Table 8. Energy Demand at the Wheel for a Class 3-4 Truck and a Class 6-7 Truck/Bus

\begin{tabular}{c|c|c}
\hline Test Cycle & $\begin{array}{c}\text { Class 3-4 Medium Truck } \\
\text { (kWh/30 mi) }\end{array}$ & $\begin{array}{c}\text { Class 6-7 Truck/Bus } \\
\text { (kWh/30 mi) }\end{array}$ \\
\hline CBD & 25 & 46 \\
CBDtrk & 22 & 40 \\
NYbus & 27 & 57 \\
NYtrk & 30 & 55 \\
NYGTC & 19 & 35 \\
\hline Average & 25 & 47 \\
\hline
\end{tabular}

\section{DESIGN CRITERIA}

One of the most important HEV design criteria is to avoid compromising vehicle performance. Assuming the weight increase of a heavy HEV can be neglected (this assumption is generally valid for heavy trucks, particularly those that operate near the gross weight limit), this means that the HEV's peak engine-plus-motor power should be no less than the peak power of its conventional ICE vehicle counterpart.

For a CV-like HEV design, the starting point is to size the on-board IC engine, which is about $98 \mathrm{~kW}$ (131 hp) for a Class 3-4 truck and $93 \mathrm{~kW}$ (125 hp) for a Class 6-7 truck. The battery pack will be sized to provide supplemental power to match the peak power rating of the original IC engine. Table 9a gives the HEV design criteria for a grid-independent, CV-like heavy hybrid vehicle.

For an EV-like HEV design, the key issue is to size the battery pack to match the energy requirement for 30 miles of pure-electric range, which is about $25 \mathrm{kWh}$ for a Class 3-4 truck and $47 \mathrm{kWh}$ for a Class 6-7 truck. The on-board engine should provide limp-home capability. The traction motor is sized to match the peak power rating of the original IC engine ${ }^{2}$. Inverter, generator, and motor gear drive should also be sized accordingly for a series-configured HEV only. Table $9 \mathrm{~b}$ gives the HEV design criteria for a grid-dependent, EV-like heavy hybrid vehicle.

Table 9. HEV Design Criteria Matrix

a. Grid-Independent, CV-like Vehicle

\begin{tabular}{|c|c|c|}
\hline Item & Parallel & Series \\
\hline Engine & \multicolumn{2}{|c|}{$\begin{array}{c}55 \text { mph @ } 5 \% \text { grade (Class 3-4), } \\
60 \text { mph on level ground (Class 6-7) }\end{array}$} \\
\hline Battery & \multicolumn{2}{|c|}{ Supplementary power to match peak power } \\
\hline $\begin{array}{l}\text { Traction motor/ } \\
\text { inverter }\end{array}$ & Match battery power & Match peak power \\
\hline Generator & - & Match APU power \\
\hline $\begin{array}{l}\text { Engine power } \\
\text { transmission }\end{array}$ & Match APU power & - \\
\hline Motor gear drive & Match motor power & Match motor power \\
\hline Pure-electric range & - & $-{ }^{-}$ \\
\hline Control strategy & Load-following & $\begin{array}{l}\text { Load-following/ } \\
\text { thermostatic }\end{array}$ \\
\hline
\end{tabular}

b. Grid-Dependent, EV-like Series-Configured Vehicle

\begin{tabular}{|l|c|}
\hline Item & Criteria \\
\hline Engine & Small ICE - limp-home-capable \\
\hline Battery & Based on pure EV range \\
\hline Traction motor/inverter & Match peak power \\
\hline Generator & Match engine power \\
\hline Pure-electric range & 30 miles \\
\hline Motor gear drive & Match motor power \\
\hline Control strategy & Thermostatic \\
\hline
\end{tabular}

\footnotetext{
${ }^{2}$ To keep constant performance level. The traction motor is generally not sized to match the peak power of the battery pack, which is usually extremely high because of the high capacity requirement of the battery.
} 
Table 11. Engine Downsizing (CV-like)

On the basis of the HEV design matrix (Tables 9a and $9 b$ ), as well as power and energy demand (Tables 7 and 8), we can establish component sizing for these HEVs. Table 10a provides component sizing for a gridindependent, CV-like HEV; Table 10b does the same for a grid-dependent, EV-like HEV.

Table 10. HEV Component Sizing a. Grid-Independent, CV-like Vehicle

\begin{tabular}{|c|c|c|c|c|}
\hline \multirow{2}{*}{ Item } & \multicolumn{2}{|c|}{$\begin{array}{c}\text { Class 3-4 } \\
\text { Delivery Trucks }\end{array}$} & \multicolumn{2}{c|}{$\begin{array}{c}\text { Class 6-7 } \\
\text { Trucks/Buses }\end{array}$} \\
\cline { 2 - 5 } & Parallel & Series & Parallel & Series \\
\hline Engine (kW) & \multicolumn{2}{|c|}{98} & \multicolumn{2}{|c|}{93} \\
\hline Battery (kW) & \multicolumn{2}{|c|}{44} & \multicolumn{2}{|c|}{63} \\
\hline Motor/inverter (kW) & 40 & 128 & 57 & 141 \\
\hline Generator (kW) & - & 93 & - & 89 \\
\hline $\begin{array}{c}\text { Power transmission } \\
\text { (kW) }\end{array}$ & 98 & - & 93 & - \\
\hline Motor gear (kW) & 40 & 128 & 57 & 141 \\
\hline Battery capacity (kWh) & \multicolumn{2}{|c|}{4.7} & & \multicolumn{2}{|c|}{6.8} \\
\hline Battery weight (kg) & \multicolumn{2}{|c|}{147} & \multicolumn{2}{|c|}{211} \\
\hline
\end{tabular}

b. Grid-Dependent, EV-like Series-Configured Vehicle

\begin{tabular}{|c|c|c|}
\hline Item & $\begin{array}{c}\text { Class 3-4 } \\
\text { Delivery Trucks }\end{array}$ & $\begin{array}{c}\text { Class 6-7 } \\
\text { Trucks/Buses }\end{array}$ \\
\hline EV range (miles) & 30.0 & 30.0 \\
\hline Battery capacity $(\mathrm{kWh})^{3}$ & 51.2 & 97.1 \\
\hline Battery weight $(\mathrm{kg})$ & 1280 & 2427 \\
\hline Battery power $(\mathrm{kW})$ & 320 & 607 \\
\hline Engine $(\mathrm{kW})$ & 50 & 50 \\
\hline Engine downsizing & $65 \%$ & $68 \%$ \\
\hline Motor/inverter $(\mathrm{kW})$ & 128 & 141 \\
\hline Generator $(\mathrm{kW})$ & 48 & 48 \\
\hline Motor gear $(\mathrm{kW})$ & 128 & 141 \\
\hline
\end{tabular}

For a CV-like HEV, the on-board ICE can be significantly downsized. Tables 10a and 11 show that, for the Class 3-4 truck and Class 6-7 trucks, the on-board engine can be downsized by about 30 and $40 \%$, respectively, from the original Navistar engines. A V6 4.0-L SUV gasoline or diesel engine can be used as an on-board IC engine.

\begin{tabular}{|c|c|c|}
\hline Item & Class 3-4 Truck & Class 6-7 Truck/Bus \\
\hline $\begin{array}{c}\text { Required } \\
\text { power (kW) }\end{array}$ & $98(131 \mathrm{hp})$ & $93(125 \mathrm{hp})$ \\
\hline $\begin{array}{l}\text { Original ICE } \\
\text { power (kW) }\end{array}$ & $142(190 \mathrm{hp})$ & $157(210 \mathrm{hp})$ \\
\hline $\begin{array}{c}\text { Engine } \\
\text { downsizing }\end{array}$ & $-30 \%$ & $\sim 40 \%$ \\
\hline $\begin{array}{l}\text { Original IC } \\
\text { engine }\end{array}$ & $\begin{array}{l}\text { V87.4-LTDI } \\
190 @ 2300 \\
430 @ 1500\end{array}$ & $\begin{array}{l}\text { I6 7.7-L TDI } \\
210 @ 2300 \\
520 @ 1500\end{array}$ \\
\hline $\begin{array}{l}\text { Sample HEV } \\
\text { engines }\end{array}$ & \multicolumn{2}{|c|}{$\begin{array}{l}\text { V6 4.0-L Explorer engine (160@ @ 4200, } 225 @ \\
\text { 2750) or Detroit Diesel SUV DEL LTA Engine, V6 } \\
\text { 4.0-L (210@ @ 4000, } 340 @ 2000)\end{array}$} \\
\hline
\end{tabular}

\section{HYBRID HEAVY VEHICLE ENERGY SAVINGS POTENTIALS}

We assess the potential energy savings possible by reducing inefficient vehicle operating conditions.

Despite the variety of HEV design strategies, many hybrid vehicles have the following basic features: (1) engine-off capability during conditions where a conventional engine would be in idling and/or deceleration modes, (2) a regenerative braking mechanism, and (3) improved internal-combustion engine efficiency by running the engine at more favorable operating conditions. Of course, added features for hybridization may impose penalties as well, such as added vehicle weight, energy loss associated with on-board battery charging, and a more complicated transmission system. Experience with today's light-duty HEVs shows that technical limits exist on how much wasted energy can be recovered in practice from the vehicle hybridization process. For example, it is impractical to shut down an engine every single second when the vehicle is decelerating, especially during very brief decelerations that last only a few seconds. Technically, it is also impossible to recover $100 \%$ of braking energy; a more practical goal is about $50 \%$, reflecting about $70 \%$ recovery efficiency from vehicle wheels and $70 \%$ efficiency in the transmission and charging process. During urban driving, the transmission efficiency for conventional heavy-duty trucks can be as low as $53 \%$. Hybridization can improve transmission efficiency significantly during low-speed urban driving. For an optimal hybrid design, the relative engine mechanical efficiency can also be improved significantly by both engine downsizing and an energy management control strategy. Table 12 defines the practical energy saving scenario. More detailed analysis of energy saving scenarios can be found in References 12 and 13 .

\footnotetext{
${ }^{3}$ Battery capacity requirement is determined by assuming $80 \%$ drivetrain efficiency and battery SOC ranging from 20 to $80 \%$; thus, it equals energy demand at the vehicle wheel, divided by $0.8 \times 0.6(0.48)$
} 
Table 12. Energy Savings Scenarios for Hybrid Vehicles

\begin{tabular}{c|cc}
\hline & & CV-like \\
Energy Savings Scenario & CV & HEV \\
\hline Idle Energy Use Reducible & $0 \%$ & $70 \%$ \\
Braking Energy Recoverable & $0 \%$ & $50 \%$ \\
Transmission Efficiency $^{4}$ & $\sim 54 \%$ & $>70 \%$ \\
Engine Mechanical Efficiency $^{4}$ & $\sim 75 \%$ & $>80 \%$ \\
\hline
\end{tabular}

The practical scenario, which reflects energy savings in terms of today's technology, provides a more realistic picture of what we can expect from hybridizing heavy vehicles. The efficiency gains associated with such measures as vehicle weight reduction and aerodynamic improvements are not considered, because such measures would also benefit conventional-technology vehicles. We focus on benefits associated solely with hybridization.

Table 13 shows the modeling results of energy saved from different operational modes for the Class 3-4 truck by test cycles under the practical energy savings scenario. The Idle column represents energy saved from partially $(70 \%)$ eliminating engine idling operation; the Regen. (regeneration) column represents energy saved from partially $(50 \%)$ recovering braking energy loss; the Trans. (transmission) column represents energy saved from improved transmission efficiency; and the PartLoad column represents energy saved if the engine is operated at an average of $80 \%$ of its peak efficiency. As expected, the table shows that the energy savings from different options differ by cycles. For example, under the NYbus cycle, the greatest energy savings $(24 \%)$ is from recovering energy lost during vehicle braking. For the NTGTC, the greatest energy savings would be from engine idle-off $(25 \%)$ and transmission efficiency improvements $(29 \%)$. Vehicles driving in the NYGTC have the highest practical potential for energy savings, reaching $63 \%$. Vehicles driving in the NYtrk cycle have the lowest energy savings potential, $32 \%$.

Table 13. Energy Saved by Operational Modes for the Class 3-4 Truck

\begin{tabular}{|c|ccccc|}
\hline & \multicolumn{5}{|c|}{ Energy Saved } \\
\hline & Idle & $\begin{array}{c}\text { Regen. } \\
\text { Cycle }\end{array}$ & $\begin{array}{c}\text { Trans. } \\
(\%)\end{array}$ & $\begin{array}{c}\text { Part-load } \\
(\%)\end{array}$ & $\begin{array}{c}\text { Total } \\
(\%)\end{array}$ \\
\hline CBD & 3.6 & 19.1 & 16.4 & 8.8 & 40.8 \\
CBDtrk & 6.7 & 13.6 & 21.6 & $(3.2)$ & 35.5 \\
NYbus & 18.6 & 24.4 & 20.2 & 6.5 & 55.4 \\
NYtrk & 11.5 & 20.9 & 2.3 & 1.7 & 32.0 \\
NYGTC & 25.4 & 10.8 & 29.4 & 9.8 & 63.2 \\
\hline
\end{tabular}

\footnotetext{
${ }^{4}$ For an optimally designed hybrid vehicle, the battery chargedischarge round-trip efficiency can reach $80 \%$, equivalent to an average engine's mechanical efficiency.

${ }^{5}$ Total energy savings are not a simple summation of individual savings, because the savings from individual modes are not entirely independent of each other.
}

Table 14 shows the modeling results for fuel economy and fuel economy gains of the Class 3-4 truck under the practical energy savings scenario by test cycles. The fuel economy gains range from about $47 \%$ under the New York Truck Cycle to more than $170 \%$ under the New York City Garbage Truck Cycle. The average fuel economy gain over these five urban cycles is about $93 \%$.

Similar analysis for the Class 6-7 truck under the practical energy savings scenario was done as well. Table 15 presents the fuel economy and fuel economy gains for the Class 6-7 truck under five individual test cycles.

Table 14. Fuel Economy Gain for the Class 3-4 Truck

\begin{tabular}{|c|c|c|c|}
\hline Cycle & $\begin{array}{c}\mathrm{CV} \\
(\mathrm{mpg})\end{array}$ & $\begin{array}{l}\text { HEV } \\
\text { (mpg) }\end{array}$ & $\begin{array}{c}\text { Gain } \\
(\%)\end{array}$ \\
\hline $\mathrm{CBD}$ & 7.9 & 13.3 & 68.9 \\
\hline CBDtrk & 8.2 & 12.7 & 55.1 \\
\hline NYbus & 4.7 & 10.5 & 124.2 \\
\hline NYtrk & 7.2 & 10.6 & 47.1 \\
\hline NYGTC & 4.4 & 11.9 & 171.8 \\
\hline Average & 6.5 & 11.8 & 93 \\
\hline
\end{tabular}

Table 15 shows that, for Class 6-7 trucks, the fuel economy gains due to hybridization range from about $30 \%$ under the New York Truck Cycle to more than $140 \%$ under the New York City Garbage Truck Cycle. The average fuel economy gain over these urban cycles is about $71 \%$.

Table 15. Fuel Economy Gain for the Class 6-7 Truck

\begin{tabular}{c|c|c|c}
\hline Cycle & $\begin{array}{c}\text { CV } \\
(\mathrm{mpg})\end{array}$ & $\begin{array}{c}\text { HEV } \\
(\mathrm{mpg})\end{array}$ & $\begin{array}{c}\text { Gain } \\
(\%)\end{array}$ \\
\hline CBD & 4.7 & 6.8 & $\mathbf{4 5 . 5}$ \\
CBDtrk & 5.0 & 7.0 & $\mathbf{3 8 . 7}$ \\
NYbus & 3.0 & 6.0 & $\mathbf{1 0 0 . 7}$ \\
NYtrk & 4.4 & 5.7 & 30.1 \\
NYGTC & 3.0 & 7.2 & $\mathbf{1 4 0 . 5}$ \\
\hline Average & 4.0 & 6.5 & $\mathbf{7 1}$ \\
\hline
\end{tabular}

\section{INVESTMENT COST AND PAYBACK TIME ANALYSIS}

We estimate the incremental cost of vehicle hybridization for Class 3-7 vehicles. The costs are estimated on the basis of high-volume mass production and substantial reduction in electrical component costs through the years 2005, 2010, 2015, and 2020.

The basic assumption behind the cost data given here is that a hybrid truck's body and frame would remain essentially the same as those of the current ICEpowered trucks. The common-component cost share of 
the total cost is approximately $70 \%$ for medium trucks. The costs of generator, inverter and power electronics, motor, transmission/gear drive, battery pack, system control, and other components (such as HVAC and electrical brakes) are added to arrive at the hybrid truck cost. The cost savings of downsizing the on-board IC engine are also included. By our estimate, a typical Class 3-5 truck would cost the original equipment manufacturer (OEM) approximately $\$ 24,000$. Such a truck would come without a van or other kind of structure over the frame. Consequently, the OEM cost of its common components would be $\$ 16,800$.

The components cost data reported here are first estimated as cost to the OEM. The final price to consumers is computed by applying a factor to include overhead, R\&D and engineering, warranty, transportation, advertising and dealer support, and profit. Most of the truck components are outsourced and assembled by the manufacturer. The delivered truck has a powertrain, cab, and frame only. A body is added according to the buyer's intended use. $A$ van-type body would cost nearly $\$ 5,000-6,000$ for a medium truck. The sum of component costs (excluding the body) is multiplied by a factor of 1.3 (i.e., a $30 \%$ increase) to arrive at the manufacturer's suggested retail price. This would put the common-component costs for a Class 5 truck at $\$ 21,840$. The battery pack should be treated differently; a factor of 1.15 is used to account for warranty and profit. The costs and cycle times of both lead acid and $\mathrm{NiMH}$ batteries are estimated from published information [14-19].

In estimating the cost of electric drive components, we have considered three items typical of heavy vehicles: (1) low volume, (2) necessity to produce components to meet the most demanding duty cycle, and (3) need for a rugged design so that the components can survive in a hostile environment and be longer-lasting than light-duty vehicle components. Consequently, the electric drive components are expected to cost the OEM more. compared to similar light-duty components.

\section{INCREMENTAL COST OF VEHICLE HYBRIDIZATION}

We analyze the incremental investment cost for hybridizing Class 3-7 heavy vehicles. In the analysis, two battery types are considered: lead acid battery and $\mathrm{NiMH}$ battery. The lead acid battery is very attractive for heavy HEV applications, primarily because of its low cost. Also, for a heavy HEV, battery weight and packaging are not so big a concern as for a passenger car. The advantages of the NiMH battery are higher specific power and specific energy, as well as longer calendar and cycle lives. However, the NiMH battery is much more expensive than the lead acid battery.

We analyze both CV-like and EV-like hybrid trucks. For CV-like hybrids, both parallel and series configurations are considered. For the EV-like hybrid, only the series configuration is considered.

\section{Estimates of Incremental Costs by Year 2005}

Table 16 presents detailed estimates of the incremental cost of vehicle hybridization for year 2005, based on an internal cost model developed by the authors, for gridindependent, CV-like Class 3-4 and 6-7 heavy vehicles with lead-acid $(\mathrm{PbA})$ batteries.

Table 16 shows that on-board engine downsizing (Table 11) saves about $\$ 1,900$ for a Class $3-4$ hybrid truck and $\$ 2,800$ for a Class 6-7 hybrid truck/bus.

Table 16. Incremental Cost of Vehicle Hybridization (2005, PbA battery, grid-independent, CV-like)

\begin{tabular}{|l|c|c|c|c|}
\hline & \multicolumn{2}{c|}{$\begin{array}{c}\text { Class 3-4 Delivery } \\
\text { Trucks }\end{array}$} & \multicolumn{2}{c|}{$\begin{array}{c}\text { Class 6-7 } \\
\text { Trucks/Buses }\end{array}$} \\
\hline \multicolumn{1}{|c|}{ Item } & Parallel & Series & Parallel & Series \\
\hline Engine (\$) & \multicolumn{2}{|c|}{$(1,933)$} & \multicolumn{2}{|c|}{$(2,785)$} \\
\hline Battery (\$) $\times 2.5$ & \multicolumn{2}{|c|}{2,428} & \multicolumn{2}{c|}{3,498} \\
\hline Motor (\$) & 1,380 & 3,723 & 1,845 & 4,081 \\
\hline Generator (\$) & - & 2,798 & - & 2,685 \\
\hline Inverter (\$) & 2,273 & 5,587 & 2,931 & 6,093 \\
\hline Transmission (\$) & - & $(3,282)$ & - & $(3,588)$ \\
\hline Motor gear drive (\$) & 312 & 836 & 360 & 927 \\
\hline System control et al. & \multicolumn{5}{|c|}{1,300} \\
\hline Total & $\$ 5,760$ & $\$ 11,458$ & $\$ 7,149$ & $\$ 12,211$ \\
\hline
\end{tabular}

For the parallel configuration, the largest cost item is the battery pack: it costs about $\$ 2,400$ for a Class 3-4 truck and $\$ 3,500$ for a Class 6-7 truck. (The battery pack cost includes the replacement cost.) The maximum life of a lead acid battery is about four years. We assume the vehicle is used intensively for 12 years; thus, on average, the lead-acid battery needs to be replaced twice during this period. With an assumed discount rate of $5 \%$, the battery cost must be multiplied by a factor of 2.5 to reflect its replacement cost. The overall incremental cost is about $\$ 5,760$ for a Class $3-4$ hybrid truck and $\$ 7,150$ for a Class 6-7 truck. These cost figures represent $15-20 \%$ of the cost of the corresponding conventional trucks.

For the series configuration, the costs of motor, generator and inverter dominate. The series hybrid does not need power transmission, so a cost saving of $\$ 3,300-3,600$ can be achieved for both hybrid vehicles. But the overall cost of a series hybrid is about $\$ 5,000$ 5,700 more than that of a parallel hybrid.

Table 17 presents detailed estimates of the incremental costs of vehicle hybridization for CV-like Class 3-4 and 6-7 heavy vehicles with NiMH batteries. 
Table 17. Incremental Cost of Vehicle Hybridization, (2005, NiMH battery, grid-independent, CV-like)

\begin{tabular}{|c|c|c|c|c|}
\hline & \multicolumn{2}{|c|}{$\begin{array}{c}\text { Class 3-4 Delivery } \\
\text { Trucks }\end{array}$} & \multicolumn{2}{|c|}{$\begin{array}{c}\text { Class 6-7 } \\
\text { Trucks/Buses }\end{array}$} \\
\hline Item & Parallel & Series & Parallel & Series \\
\hline Engine (\$) & \multicolumn{2}{|c|}{$(1,933)$} & \multicolumn{2}{|c|}{$(2,785)$} \\
\hline Battery $(\$) \times 1.5$ & \multicolumn{2}{|c|}{6,304} & \multicolumn{2}{|c|}{9,082} \\
\hline Motor $(\$)$ & 1,412 & 3,809 & 1,888 & 4,175 \\
\hline Generator (\$) & - & 2,863 & - & 2,747 \\
\hline Inverter (\$) & 2,325 & 5,716 & 2,998 & 6,234 \\
\hline Transmission (\$) & - & $(3,282)$ & - & $(3,588)$ \\
\hline Motor gear drive (\$) & 312 & 836 & 360 & 927 \\
\hline System control et al. & \multicolumn{4}{|c|}{1,300} \\
\hline Total & $\$ 9,720$ & $\$ 15,613$ & $\$ 12,843$ & $\$ 18,092$ \\
\hline
\end{tabular}

Table 17 shows that, for both configurations, the cost of the battery pack has increased dramatically: it exceeds $\$ 6,300$ for a Class 3-4 truck and $\$ 9,000$ for a Class 6-7 truck. We estimate the lifetime of a NiMH battery at about seven years. Thus, the battery cost needs to be multiplied by a factor of 1.5 to reflect its replacement cost over the 12-year lifetime of the vehicie. The overall incremental costs are about $\$ 9,700-16,000$ for a Class 3-4 hybrid truck and about $\$ 13,000-18,000$ for a Class 67 truck.

Table 18 presents detailed estimates of the incremental cost of vehicle hybridization for EV-like Class 3-4 and 67 heavy vehicles with lead-acid batteries. An EV-like hybrid requires significant pure-electric range (30 miles under our assumption), so the cost of the battery pack really dominates the incremental cost of hybridization. The overall incremental cost for an EV-like hybrid is about $\$ 26,000$ for a Class $3-4$ truck and about $\$ 45,000$ for a Class 6-7 truck.

Table 18. Incremental Cost of Vehicle Hybridization (2005, PbA battery, grid-dependent, EV-like, series)

\begin{tabular}{|l|c|c|}
\hline \multicolumn{1}{|c|}{ Item } & $\begin{array}{c}\text { Class 3-4 Delivery } \\
\text { Trucks }\end{array}$ & $\begin{array}{c}\text { Class 6-7 } \\
\text { Trucks/Buses }\end{array}$ \\
\hline Engine $(\$)$ & $(4,029)$ & $(4,684)$ \\
\hline Battery $(\$) \times 2.5$ & 20,606 & 39,069 \\
\hline Motor $(\$)$ & 3,723 & 4,081 \\
\hline Generator $(\$)$ & 1,591 & 1,591 \\
\hline Inverter $(\$)$ & 5,587 & 6,093 \\
\hline Transmission $(\$)$ & $(3,282)$ & $(3,588)$ \\
\hline Motor gear drive (\$) & 836 & 927 \\
\hline System control et al. & 1,300 & 1,300 \\
\hline Total & $\$ 26,333$ & $\$ 44,789$ \\
\hline
\end{tabular}

Figure 4, which summarizes the incremental costs of these different types of hybrid vehicles, clearly shows that the CV-like, parallel configured HEVs are the most cost-effective.

\section{Future Year Projection}

We have also projected the future year costs of CV-like hybrid trucks. Essentially, two factors affect the future cost projection: (1) the decreasing cost of various HEV components due to increased production volume and (2) the reduced battery replacement costs due to increased battery lifetime. Figure 5 shows the incremental costs of CV-like hybrid trucks with lead-acid batteries in the years $2005,2010,2015$, and 2020 , respectively. It shows that, for a parallel-configured Class 3-4 hybrid truck, the incremental costs are projected to decrease from about $\$ 5,800$ in 2005 to about $\$ 3,000$ in 2020 , or about a $48 \%$ decrease. For a parallel-configured Class 6-7 hybrid truck, the incremental costs are projected to decrease from over $\$ 7,100$ in 2005 to about $\$ 3,300$ in 2020 , or about a $53 \%$ decrease.

Figure 4. Incremental Cost of Vehicle Hybridization, 2005

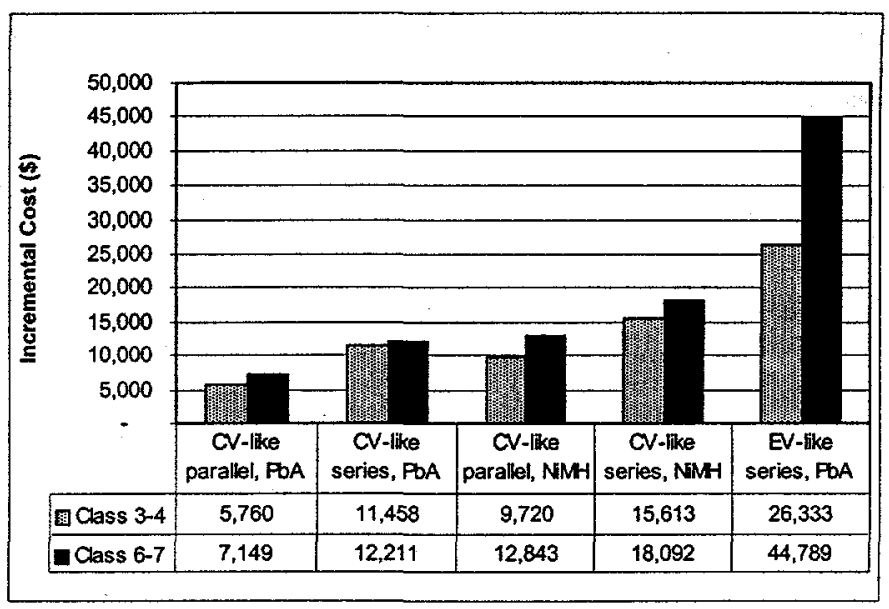

Figure 5. Incremental Costs of CV-like Hybrid Trucks with Lead-Acid Batteries, 2005, 2010, 2015, and 2020

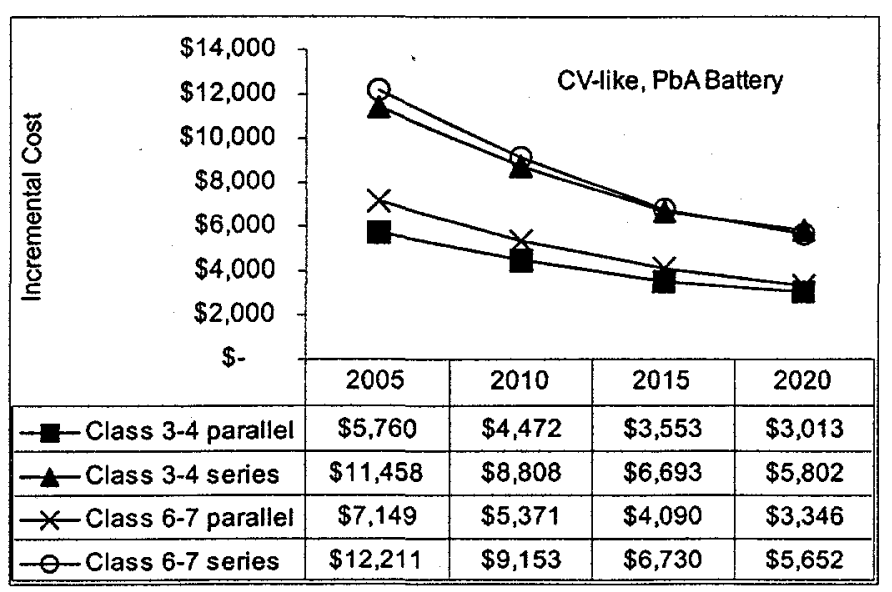

Figure 6 shows the incremental costs of CV-like hybrid trucks with NiMH batteries in 2005, 2010, 2015, and 2020 , respectively. For a parallel-configured Class 3-4 hybrid truck, the incremental costs are projected to decrease from about $\$ 9,700$ in 2005 to about $\$ 4,700$ in 2020 , or about a $55 \%$ decrease. For a parallel- 
configured Class 6-7 hybrid truck, the incremental costs are projected to decrease from over $\$ 13,000$ in 2005 to about $\$ 5,700$ in 2020 , or about a $59 \%$ decrease.

\section{INVESTMENT PAYBACK TIME ANALYSIS}

This section assesses the simple investment payback time for hybridizing Class 3-7 trucks. To simplify the analysis, we only take into account the annual fuel savings associated with vehicle hybridization ${ }^{6}$.

We first estimate the annual vehicle miles of travel (VMT) associated with different usage of the vehicle. Table 19 presents our estimation of Class 3-7 commercial vehicle VMT by driving cycles, assuming 250 working days a year and 8 working hours a day. The annual VMT ranges from about 4,700 miles for a garbage truck driving in New York City to more than 25,000 miles for vehicles driving under the CBD cycle.

Figure 6. Incremental Costs of CV-like Hybrid Trucks with NiMH Batteries, 2005, 2010, 2015, and 2020

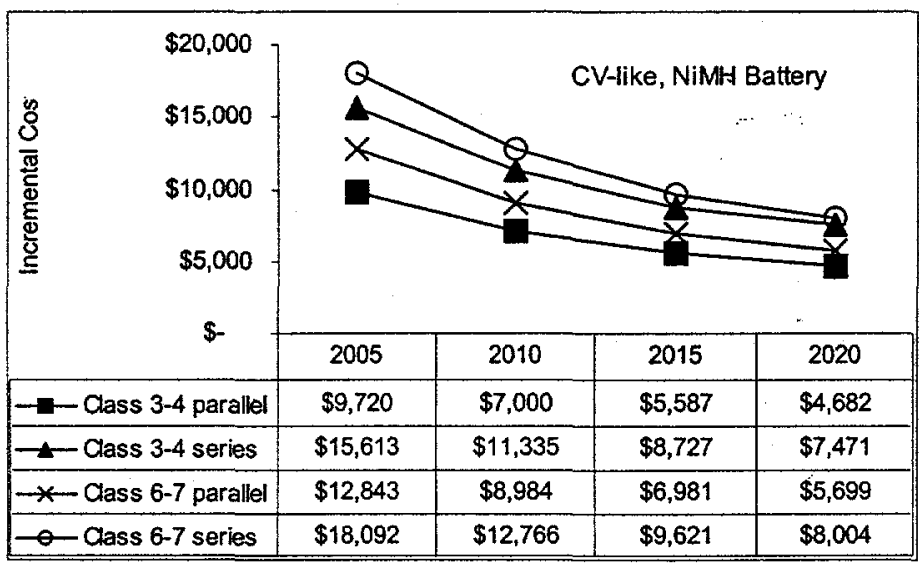

Tables 20 and 21 present the simple payback time analysis for CV-like Class $3-4$ and Class 6-7 hybrid vehicles with lead-acid batteries, for both parallel and series configurations. We here assume the diesel price of $\$ 1.20$ per gallon. Both tables show that the payback time of hybridization is sensitive to the driving cycles, as is further demonstrated by Figure 7.

Figure 7. Payback Time for Investment by Cycles for CV-like, Parallel Hybrid with Lead-Acid Battery, 2005

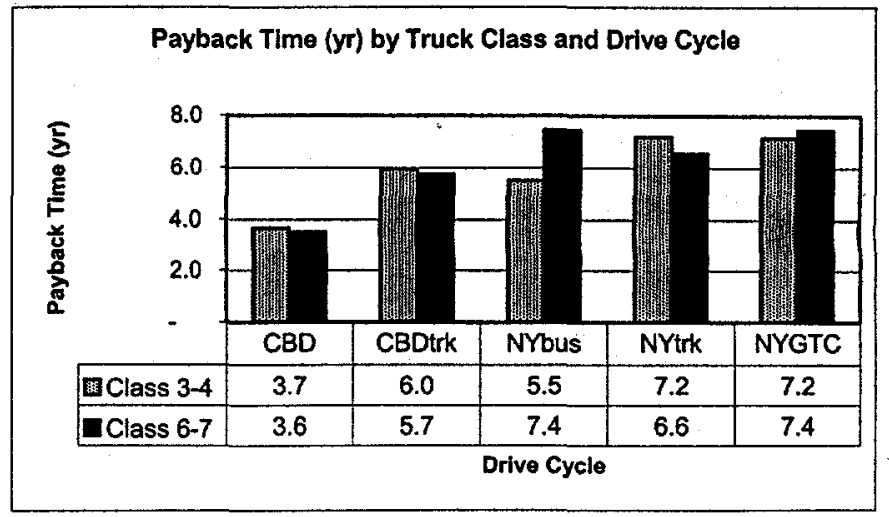

Tables 20 and 21 and Figure 7 show that, for a parallelconfigured Class 3-4 hybrid truck, the payback time ranges from about 3.7 years under the CBD cycle to about 7.2 years under both NYtrk and NYGTC cycles. On average, the payback time for a Class 3-4 hybrid truck is about 5.9 years. For a parallel-configured Class 6-7 hybrid truck, the payback time ranges from about 3.6 years under the CBD cycle to about 7.4 years under both NYbus and NYGTC cycles. On the average, the payback time for a Class 6-7 hybrid truck/bus is about 5.6 years.

\footnotetext{
${ }^{6}$ Other HEV benefits: (1) by operating in a narrower speed range, engines do not have to be rebuilt or repaired as frequently; (2) because of regenerative braking, there is less wear on brakes; And (3) less frequent repair means reduced vehicle downtime as well.
} 
Table 19. Annual Vehicle Miles of Travel (VMT)

\begin{tabular}{|c|c|c|c|c|}
\hline Test Cycle & $\begin{array}{c}\text { Ave. Speed } \\
\text { (mph) }\end{array}$ & $\begin{array}{c}\text { Days/year } \\
\text { (days) }\end{array}$ & $\begin{array}{c}\text { Hours/day } \\
\text { (hours) }\end{array}$ & $\begin{array}{c}\text { VMT } \\
\text { (miles) }\end{array}$ \\
\hline CBD & 12.6 & 250 & 8 & 25,160 \\
CBDtrk & 9.2 & 250 & 8 & 18,400 \\
NYbus & 3.7 & 250 & 8 & 7,380 \\
NYtrk & 7.6 & 250 & 8 & 15,120 \\
NYGTC & 2.3 & 250 & 8 & 4,660 \\
\hline Average & 7.1 & 250 & 8 & 14,150 \\
\hline
\end{tabular}

Table 20. Payback Time Analysis for Class 3-4 Delivery Trucks, PbA Battery, 2005

\begin{tabular}{|c|c|c|c|c|c|c|c|c|c|c|}
\hline \multirow[b]{2}{*}{$\begin{array}{c}\text { Class } 4-5 \\
\text { Medium } \\
\text { Trucks }\end{array}$} & \multicolumn{4}{|c|}{ Conventional Vehicle } & \multicolumn{4}{|c|}{ Hybrid Vehicle } & \multicolumn{2}{|c|}{ Payback time } \\
\hline & $\begin{array}{l}\text { Fuel } \\
\text { Eco- } \\
\text { nomy }\end{array}$ & $\begin{array}{l}\text { Annual } \\
\text { Driving }\end{array}$ & $\begin{array}{l}\text { Fuel } \\
\text { Use }\end{array}$ & $\begin{array}{c}\text { Driving } \\
\text { Cost }\end{array}$ & $\begin{array}{l}\text { HEV Fuel } \\
\text { Eco- } \\
\text { nomy }\end{array}$ & $\begin{array}{c}\text { HEV Fuel } \\
\text { Use }\end{array}$ & $\begin{array}{c}\text { HEV } \\
\text { Driving } \\
\text { Cost }\end{array}$ & $\begin{array}{c}\text { HEV } \\
\text { Driving } \\
\text { Annual } \\
\text { Saving }\end{array}$ & $\begin{array}{l}\text { CV-like } \\
\text { Parallel }\end{array}$ & $\begin{array}{l}\text { CV-like } \\
\text { Series }\end{array}$ \\
\hline & $(\mathrm{mpg})$ & (miles) & (gal) & $(\$)$ & $(\mathrm{mpg})$ & (gal) & $(\$)$ & (\$) & $(y r)$ & $(y r)$ \\
\hline $\mathrm{CBD}$ & 7.9 & 25,160 & 3,193 & 3,831 & 13.3 & 1,892 & 2,270 & 1,561 & 3.7 & 7.3 \\
\hline CBDtrk & 8.2 & 18,400 & 2,256 & 2,707 & 12.7 & 1,449 & 1,739 & 968 & 6.0 & 11.8 \\
\hline NYbus & 4.7 & 7,380 & 1,576 & 1,892 & 10.5 & 703 & 843 & 1,049 & 5.5 & 10.9 \\
\hline NYtrk & $\overline{7.2}$ & 15,120 & 2,095 & 2,514 & 10.6 & 1,427 & $\overline{1,712}$ & 802 & 7.2 & 14.3 \\
\hline NYGTC & 4.4 & 4,660 & 1,061 & 1,274 & 11.9 & 392 & 470 & 804 & 7.2 & 14.3 \\
\hline Average & 6.5 & 14,150 & 2,036 & 2,443 & 11.8 & 1,172 & 1407 & 1037 & 5.9 & 11.7 \\
\hline
\end{tabular}

Table 21. Payback Time Analysis for Class 6-7 Trucks/Buses, PbA Battery, 2005

\begin{tabular}{|c|c|c|c|c|c|c|c|c|c|c|}
\hline & \multicolumn{4}{|c|}{ Conventional Vehicle } & \multicolumn{4}{c|}{ Hybrid Vehicle } & \multicolumn{2}{c|}{ Payback time } \\
\cline { 2 - 12 } $\begin{array}{c}\text { Class 6-7 } \\
\text { Vehicles }\end{array}$ & $\begin{array}{c}\text { Fuel } \\
\text { Eco- } \\
\text { nomy }\end{array}$ & $\begin{array}{c}\text { Annual } \\
\text { Driving }\end{array}$ & $\begin{array}{c}\text { Fuel } \\
\text { Use }\end{array}$ & $\begin{array}{c}\text { Driving } \\
\text { Cost }\end{array}$ & $\begin{array}{c}\text { HEV Fuel } \\
\text { Eco- } \\
\text { nomy }\end{array}$ & $\begin{array}{c}\text { HEV Fuel } \\
\text { Use }\end{array}$ & $\begin{array}{c}\text { HEV } \\
\text { Driving } \\
\text { Cost }\end{array}$ & $\begin{array}{c}\text { Driving } \\
\text { Annual } \\
\text { Saving }\end{array}$ & $\begin{array}{c}\text { CV-like } \\
\text { Parallel }\end{array}$ & $\begin{array}{c}\text { CV-like } \\
\text { Series }\end{array}$ \\
\hline & (mpg) & (miles) & (gal) & $(\$)$ & (mpg) & (gal) & $(\$)$ & $(\$)$ & $(\mathrm{yr})$ & $(\mathrm{yr})$ \\
\hline CBD & 4.7 & 25,160 & 5,376 & 6,451 & 6.8 & $\mathbf{3 , 7 0 0}$ & 4,440 & 2,011 & 3.6 & 6.1 \\
\hline CBDtrk & 5.0 & 18,400 & 3,667 & 4,400 & 7.0 & 2,630 & 3,155 & 1,245 & 5.7 & 9.8 \\
\hline NYbus & 3.0 & 7,380 & 2,467 & 2,961 & 6.0 & 1,230 & 1,475 & 1,485 & 4.8 & 8.2 \\
\hline NYtrk & 4.4 & 15,120 & 3,453 & 4,144 & 5.7 & 2,653 & 3,184 & 960 & 7.4 & 12.7 \\
\hline NYGTC & 3.0 & 4,660 & 1,553 & 1,864 & 7.2 & 647 & 777 & 1,087 & 6.6 & 11.2 \\
\hline Average & 4.0 & $\mathbf{1 4 , 1 5 0}$ & $\mathbf{3 , 3 0 3}$ & $\mathbf{3 , 9 6 4}$ & $\mathbf{6 . 5}$ & $\mathbf{2 , 1 7 2}$ & $\mathbf{2 6 0 6}$ & $\mathbf{1 3 5 8}$ & $\mathbf{5 . 6}$ & $\mathbf{9 . 6}$ \\
\hline
\end{tabular}


Future Investment Payback Time Projection

The future investment payback time is expected to decrease dramatically, as indicated by Figures 8 and 9 , largely due to the decreasing incremental cost of vehicle hybridization (Figures 5 and 6) and increasing fuel economy benefits of vehicle hybridization? ${ }^{7}$. For example, Figure 8 shows that the payback time for a CV-like, parallel-configured Class 3-4 hybrid truck with a leadacid battery pack is projected to decrease from about 5.9 years in 2005 to about 2.6 years in 2020 . For a Class $6-$ 7 hybrid truck, the payback time is projected to decrease from about 5.6 years in 2005 to about 2.1 years in 2020 .

Figure 8. Average Payback Time for CV-like Hybrids with Lead-Acid Battery: 2005, 2010, 2015, and 2020.

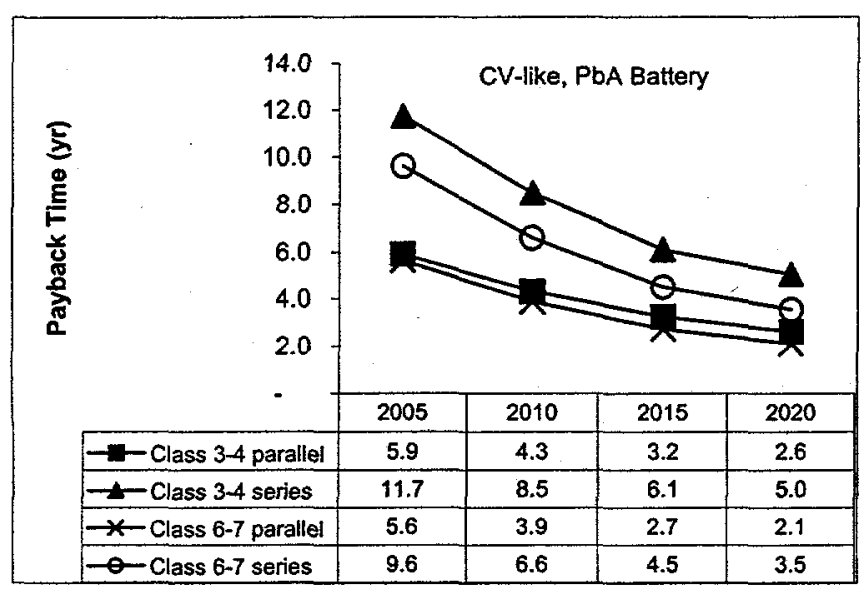

Figure 9. Average Payback Time for CV-like Hybrids with NiMH Battery: 2005, 2010, 2015, and 2020.

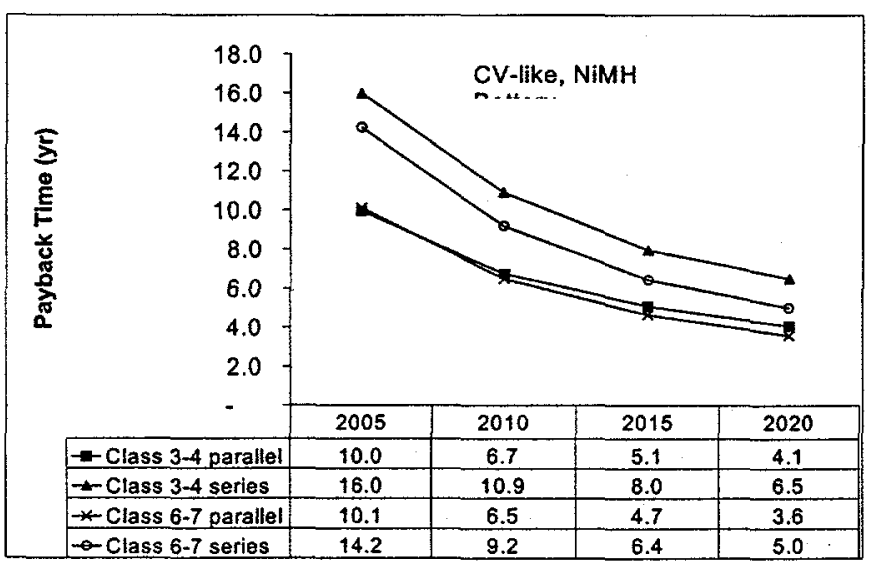

Figure 9 shows that the payback time for a CV-like, parallel-configured Class 3-4 hybrid truck with a NiMH battery pack is projected to decrease from about 10 years in 2005 to about 4.1 years in 2020 . For a Class 67 hybrid truck, the payback time is projected to decrease from about 10 years in 2005 to about 3.6 years in 2020 .

\footnotetext{
${ }^{7}$ Assuming the fuel economy benefits associated with vehicle hybridization increase by about $5 \%$ every five years, due to improving hybridization technology.
}

\section{CONCLUSIONS}

In this paper, potential energy benefits of hybridization are quantified, hybridization configuration scenarios are analyzed, and incremental cost and investment payback time of hybridization are estimated. On the basis of our analysis, we conclude that

- Hybridization can significantly reduce vehicle energy consumption.

- Fuel savings potentials depend on test cycles. Averaged over 5 urban cycles, a Class 3-4 delivery truck can improve its fuel economy by about $90 \%$, and a Class 6-7 truck/bus can improve its fuel economy by about $70 \%$.

- The grid-independent, CV-like hybrid is more costeffective than the grid-dependent, EV-like hybrid.

- The parallel configuration is more cost-effective than the series configuration.

- For CV-like hybridization, the on-board engine can be significantly downsized. A gasoline or diesel engine used for SUVS may be a good candidate for the on-board engine.

- Over the long term, the incremental cost of hybridization for a CV-like, parallel-configured Class 3-4 heavy vehicle is about $\$ 5,800$ in 2005 and $\$ 3,000$ in 2020 . For a Class 6-7 truck, it is about $\$ 7,100$ in 2005 and $\$ 3,300$ in 2020 .

- Investment payback time depends on the specific type and application of the vehicle. It averages about 6 years under urban driving conditions in 2005 and 2-3 years in 2020 .

The initial investment cost of vehicle hybridization for commercial Class 3-7 vehicles is about $15-20 \%$ of their baseline prices. The investment payback time, ranging from 4 to 7 years in 2005, depends strongly upon how the commercial vehicles are used. But the payback time comes down steadily during the next $10-15$ years, making an investment in vehicle hybridization very attractive. Due to time limitations, we have not thoroughly analyzed the emission impacts of hybridization. However, our preliminary analysis indicates that the impacts of heavy vehicle hybridization on tailpipe emissions are also very positive.

Although our analysis clearly shows that the CV-like parallel-configured HEVs are more cost-effective than the series-configured HEVs, most industry hybrid vehicles being developed and demonstrated in the United States are series-configured ${ }^{8}$. We believe that this is so for several reasons, including the following:

\footnotetext{
${ }^{8}$ However, Allison Transmission has started to introduce a parallel-configured hybrid powertrain system, the $E^{P}$ System ${ }^{\mathrm{TM}}$, for heavy-duty vehicles and will start to market them next year.
} 
1. Most early-stage hybrid development efforts were funded by state and federal government agencies on the technology side only. These research efforts largely excluded cost considerations.

2. Because truck manufacturers, unlike car makers, do not produce their own engines, it is more challenging for them to integrate the HEV systems. The parallel configuration poses more technical challenges than does the equivalent series one.

3. There is also a belief within the heavy vehicle industry that EV-like, fuel-cell-based seriesconfigured hybrid vehicles are the future of HEVs; thus, it appears reasonable to start with a series configuration to avoid future transformations.

\section{ACKNOWLEDGMENTS}

Funding for this work was provided by the U.S. Department of Energy, Office of Heavy Vehicle Technologies, directed by Dr. James J. Eberhardt. This paper is authored in part by the staff of a U.S. Government contractor under contract W-31-109-ENG38. Accordingly, the U.S. Government . retains a nonexclusive, royalty-free license to publish or reproduce this contribution, or allow others to do so, for governmental purposes.

\section{REFERENCES}

1. Burke, A.F. 1992. "Hybrid/Electric Vehicle Design Options and Evaluations." SAE Technical Paper 920447.

2. An, F., A. Frank, and M. Ross. 1996. "Meeting Both ZEV and PNGV Goals with a Hybrid Electric Vehicle - An Exploration." SAE Technical Paper 961656.

3. An, F., M. Barth, and G. Scora. 1997. "Impacts of Diverse Driving Cycles on Electric and Hybrid Electric Vehicle Performance." SAE Technical Paper 972646.

4. Quong, S., et al. 1995. "Electric Vehicle Performance in 1994 DOE Competitions." SAE Technical Paper 950178.

5. EPA, 1998. Evaluation of a Toyota Prius Hybrid System (THS). U.S. Environmental Protection Agency Report EPA420-R-98-006.

6. SAE Topical Technology Workshop on Hybrid Electric Vehicles: Here and Now (TOPTEC), SAE International, Warrendale, $\mathrm{Pa}$.

7. Ward's Automotive Yearbook. 1998. Intertec Publishing, Overland Park, Kans.

8. Xie, W., and N.N. Clark, West Virginia University, private communication, 1998.

9. An, F., M. Barth, M. Ross, and J. Norbeck. 1997. The Development of a Comprehensive Modal Emissions Model: Operating under Hot-Stabilized Conditions. Transportation Research Board Record Series 1587:52-62, Washington, D.C.

10. An, F., F. Stodolsky, and D. Santini. 1999. "Hybrid Options for Light-Duty Vehicles." SAE Technical Paper 1999-01-2929.

11. An, F., and M. Barth. 1998. "Critical Issues in Quantifying Hybrid Electric Vehicle Emissions and Fuel Consumption." SAE Technical Paper 981902.
12. An, F., F. Stodolsky, and J. Eberhardt. 1999. Fuel and Emission Impacts of Heavy Hybrid Vehicles. $32^{\text {nd }}$ ISATA Conference Proceeding, Vienna, Austria, 99CPE015, pp. 193-202.

13. Stodolsky, F., et al. 1999. "Total Fuel Cycle Impacts of Advanced Vehicles." SAE Technical Paper 199901-0322.

14. Kalhammer, F.R., A. Kozawa, C.B. Moyer, and B.B. Owens. 1995. Performance and Availability of Batteries for Electric Vehicles: Report of the Battery Technology Advisory Panel, California Air Resources Board, El Monte, Calif.

15. Vyas, A.D., H.K. Ng, D.J. Santini, and J.L. Anderson. 1997. Electric and Hybrid Electric Vehicles: A Technology Assessment Based on a Two-Stage Delphi Study. Argonne National Laboratory Report ANL/ESD-36, Argonne, III.

16. Kitada, S., S. Tange, and M. Knoshita. 1997. "Development of Hybrid Electric Vehicles at Nissan." Presented at the Annual Automotive Technology Development Customers' Coordination Meeting, Dearborn, Mich.

17. Kimura, T., M. Ikoma, and K. Kanamaru. 1997. "Nickel/Metal-Hydride Battery for Power Assist Application." Proceedings of the 14th International Electric Vehicle Symposium, EVS-14, Orlando, Fla.

18. Cooper, A., and P.T. Moseley. 1998. "Lead Acid Electric Vehicle Batteries - Improved Performance of the Affordable Option." Proceedings of the $15^{\text {th }}$ International Electric Vehicle Symposium and Exhibition, EVS-15, Brussels, Belgium.

19. Yaegashi, T. 1997. Toyota Hybrid System -THSPresented at the Annual Automotive Technology Development Customers' Coordination Meeting, Dearborn, Mich. 